IRSTI 29.27 .51

\title{
Periodic variations in time of atmospheric alpha and beta radioactive nanoparticles
}

\author{
V.V. Dyachkov ${ }^{1, *}$, Yu.A. Zaripova ${ }^{2}$, A.V. Yushkov², A.L. Shakirov ${ }^{2}$, \\ M.T. Bigeldiyeva ${ }^{2}$, K.S. Dyussebayeva ${ }^{2}$, K.E. Abramov ${ }^{2}$ \\ ${ }^{1}$ National Research Nuclear University (MEPhI), Moscow, Russia, \\ 115409, Kashirskoe shosse, 31, Moscow, Russian Federation \\ ${ }^{2}$ National Nanotechnological Laboratory of Open Type, al-Farabi Kazakh National University, \\ 71, al-Farabi Ave., 050040, Almaty, Kazakhstan \\ e-mail:*Inirp206@gmail.com
}

\begin{abstract}
Here we present time variations data of radon emanations in the surface layer of the atmosphere, measured from January 2016 to June 2018. By means of spectral analysis method, we have analyzed time variations and showed the presence of existing natural variations, mechanisms of which were described by the authors in previous works. Authors measured the activity of natural beta-active radionuclides of radon's daughter decay products (DDP) in the surface layer of the atmosphere. The measurements were performed with a beta-spectrometer "Progress" scintillation detector, which is located on the third floor of the Faculty of Physics and Technology at al-Farabi Kazakh National University (KazNU). Measurements of beta spectra were carried out with an exposure of at least for 2000 seconds and during the day up to 10 beta spectra were recorded. The built up time dependence of the integral values of the spectra shows that seasonal variations of natural beta-active radionuclides are manifested on the background of diurnal fluctuations. Thus, 1 day, 4 day, 7 day, 16 day and 30 day variations were found.
\end{abstract}

Key words: variations in time of radon; natural beta active radionuclides; coagulation; atmospheric radioactive nanoparticles.

PACS number: 23.60

\section{Introduction}

The study of spatial topologies of radon emanations in the atmospheric surface layers is extremely topical, primarily due to the direct effect of radon on human health [1]. The Earth's crust from the initial moment of its formation contains natural radioactive elements, creating a natural radiation background. Radioactive isotopes of potassium-40, rubidium- 87 and members of three radioactive families originating from uranium-238, uranium-235 and thorium-232 are present in rocks, soil, atmosphere, waters, plants and tissues of living organisms. The only gaseous product that is produced during the decay of three families of natural radionuclides is radon. 39 radon isotopes are known (all are radioactive), three of which are natural: ${ }^{119} \mathrm{Rn}$, ${ }^{220} \mathrm{Rn}$ and ${ }^{222} \mathrm{Rn}$. Under normal conditions, there is $7 * 10^{-6} \mathrm{~g}$ of radon in $1 \mathrm{~m}^{3}$ of air [2].
Despite the fact that the oncological danger of radon is known and studied for a long time [3-9], no country in the world established standards for the maintenance of radon and its daughter products in premises until 1980 . There was a need for rationing doses to the population by radon isotopes. In the Republic of Kazakhstan, these standards were also introduced [10].

\section{Experimental procedure and methodology}

The measurements were carried out by "RAMON-02A", an electronic radon radiometer and its daughters, developed in the Republic of Kazakhstan [11]. For stationary location in a room or in a specially installed radio-ecological observation station, it is intended for automatic monitoring of the content of equivalent equilibrium volumetric activity (EEVA) of radon Rn-222 in air 
in residential and industrial premises, as well as in atmospheric air. The device measures radon's EEVA in the range $4-5 * 10^{5} \mathrm{~Bq} / \mathrm{m}^{3}$. It uses an alphaspectrometric method of measurement based on surface-barrier semiconductor detectors, and an absorbent tape, designed for at least three thousand measurements, is installed as a filter material, from which the accumulated alpha activity of radon is read.

The territories of Almaty are characterized by the existence of extensive zones of tectonic faults. World literature data show that elevated levels of radon emanations are associated with existing tectonic faults. On this reason, an object located in the tectonic fault zone was selected for the study.

This work is a continuation of [12]. To measure the time topology of the radon isotopes emanation in a continuous mode in buildings and premises, we have selected room, located on the third floor at the Faculty of Physics and Technology at al-Farabi KazNU.

In order to increase the effect, i.e., to register more powerful emanations of radon isotopes, a stationary installation was installed near the large Almaty tectonic fault, on one of its branches at the campus of the university. To measure the equilibrium and nonequilibrium components of radon isotope emanation, two measuring instruments were placed in the room with positions at a height of $1 \mathrm{~m}$ from the floor level. The measurements were carried out for 10 months with a periodicity of 2 hours. The instrument is automated to collect measurement results into a common database, with which measurement results were copied to a PC every 5 days. Figure 1 shows the time dependence of radon activity in the first half of 2018.

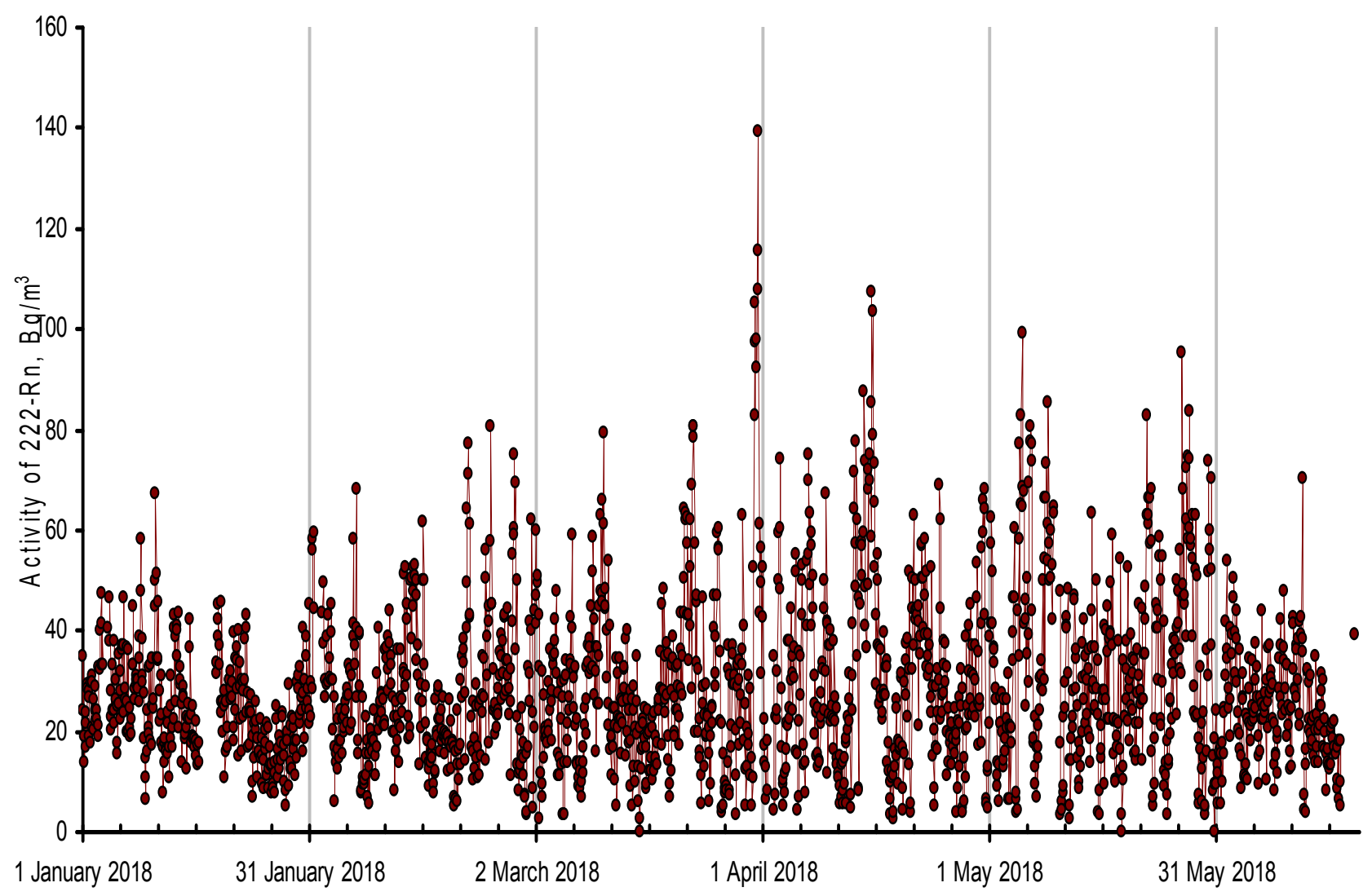

Figure 1 - The results of measurements in the experimental room using a radiometer "Ramon- $02 \mathrm{~A}$ " for the first half of 2018 


\section{Analysis of experimental data}

Variations in the emanation of radon, as it was shown in [13-21], depend on a rather large number of factors exerting their influence. In Figure 2 there are measurements of radon activity over a long period.

In addition, the time topology of the experimental data was analyzed by the method of spectral analysis, which is one of the main ones in the study of time signals and allows us to characterize the frequency composition of the measured complex spectrum. The Fourier transform is a mathematical framework that relates the time signal to its representation in the frequency domain. An important role in spectral analysis is played by statistical methods, since the signals are usually random or noisy during propagation or measurement.

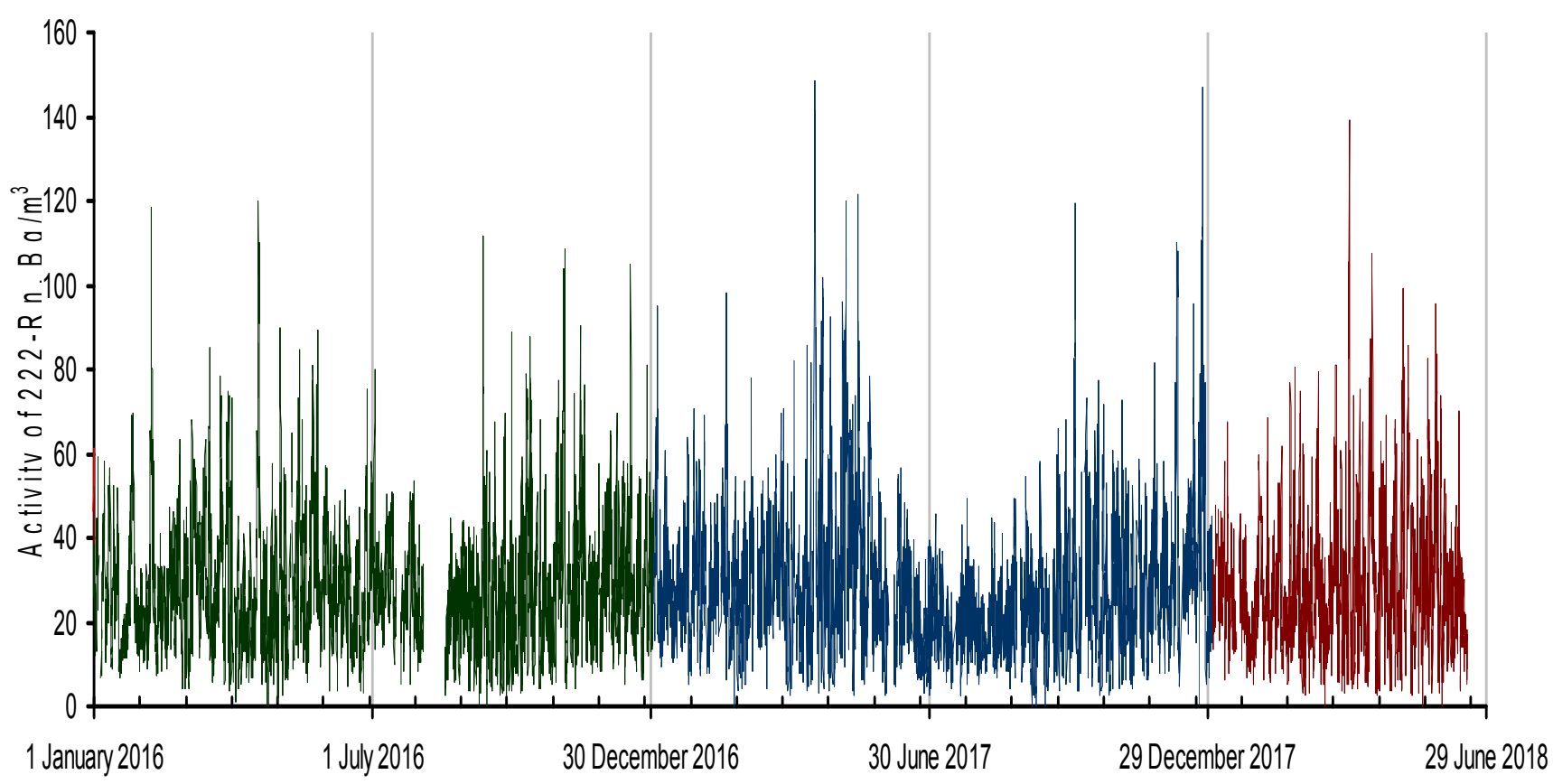

Figure 2 - The results of measurements in the experimental room using a radiometer "Ramon-02A" for the period from 2016 to the first half of 2018

Mathematically, a signal with a duration of $\mathrm{T}$ seconds is some function $\mathrm{f}(\mathrm{x})$ defined on the interval $\{0, T\}$ (where $X$ is time). Such signals can always be represented as the sum of harmonic functions (sine or cosine):

$$
f(x)=\frac{a_{0}}{2}+\sum_{k=1}^{+\infty} A_{k} \cos \left(2 \pi \frac{k}{\tau} x+\theta_{k}\right)
$$

number of the harmonic); $T$ is the length of time in which the function is defined (signal duration); $A_{k}$ is the amplitude of the $k$-th harmonic component, $\theta_{k}$ is the initial phase of the $k$-th harmonic component. This series can also be written in another form:

$$
f(x)=\sum_{k=-\infty}^{+\infty} \hat{f}_{k} e^{i 2 \pi \frac{k}{\tau} x}
$$

where $k$ is the number of the trigonometric function (the number of the harmonic component, the where $\hat{f}_{k}, \mathrm{k}$-i complex amplitude, or

$$
f(x)=\frac{a_{0}}{2}+\sum_{k=1}\left[a_{k} \cos \left(2 \pi \frac{k}{\tau} x\right)+b_{k} \sin \left(2 \pi \frac{k}{\tau} x\right)\right]
$$


The relationship between the coefficients (1) and (3) is expressed by the following formulas:

$$
A_{k}=\sqrt{a_{k}^{2}+b_{k}^{2}}, \quad \theta_{k}=\operatorname{arctg} \frac{b_{k}}{a_{k}}
$$

Note that all these three representations of the Fourier series are completely equivalent. The amplitude spectra were built up by the results of a theoretical analysis of the time variations. Figure 3 presents the amplitude spectrum, which was obtained on the basis of the description by formulas $(3,4)$ of experimental data for the first half of 2018.

In the Figure 3, circles indicate the variations that were identified in the experimental data. It is known that the mechanism of radon emanation to the surface of the Earth is complex [19-21]. In particular, from the inner surfaces of the Earth's crust radon is transported due to the diffusion of aerosols to the surface, to which due to electrostatic attraction the radon atoms coagulate. The authors carried out an areal measurements of soil samples of the surface layer of the earth for the content of betaactive radionuclides of radon daughters [22-25], taken at different points of the city of Almaty. According to these data, a map of the distribution of the content of beta-active radionuclides of radon daughters in the soil of the surface layer of the earth was constructed.

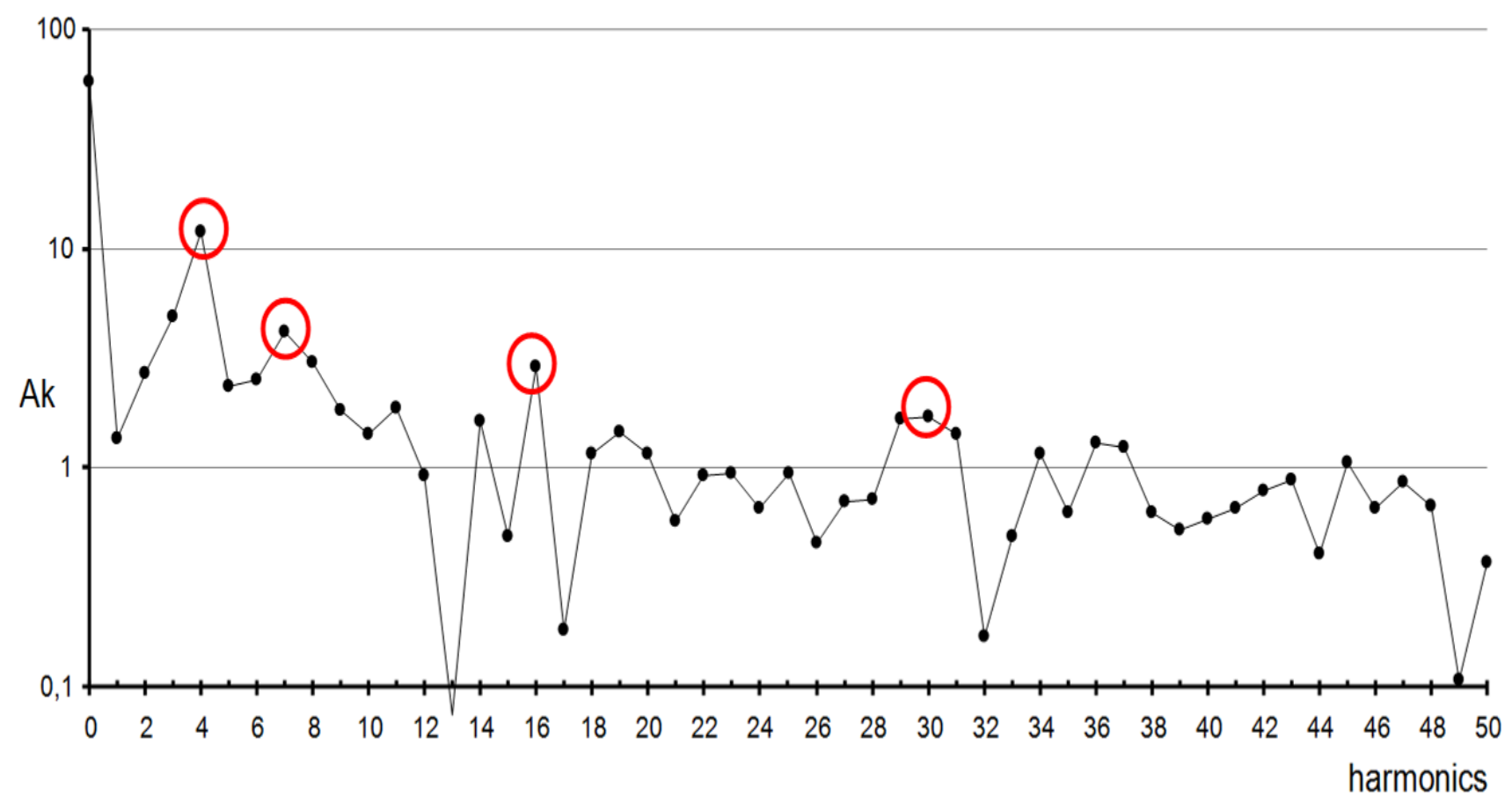

Figure 3 - Amplitude spectrum to describe experimental data on radon activity in the first half of 2018

Due to the fact that measurements of radon emanation are quite complex and the results oftenly depend on subjective factors effecting them, measurements of the activity of beta-active radionuclides of radon daughters in the surface layer of the atmosphere at various points in time were performed. Measurements of beta spectra were carried out with an exposure time of at least 2000 seconds and during the day up to 10 beta spectra were recorded. A typical beta spectrum of the radiation background is shown in Figure 4. We have also built up a time dependence of the integral values of the beta spectra. 


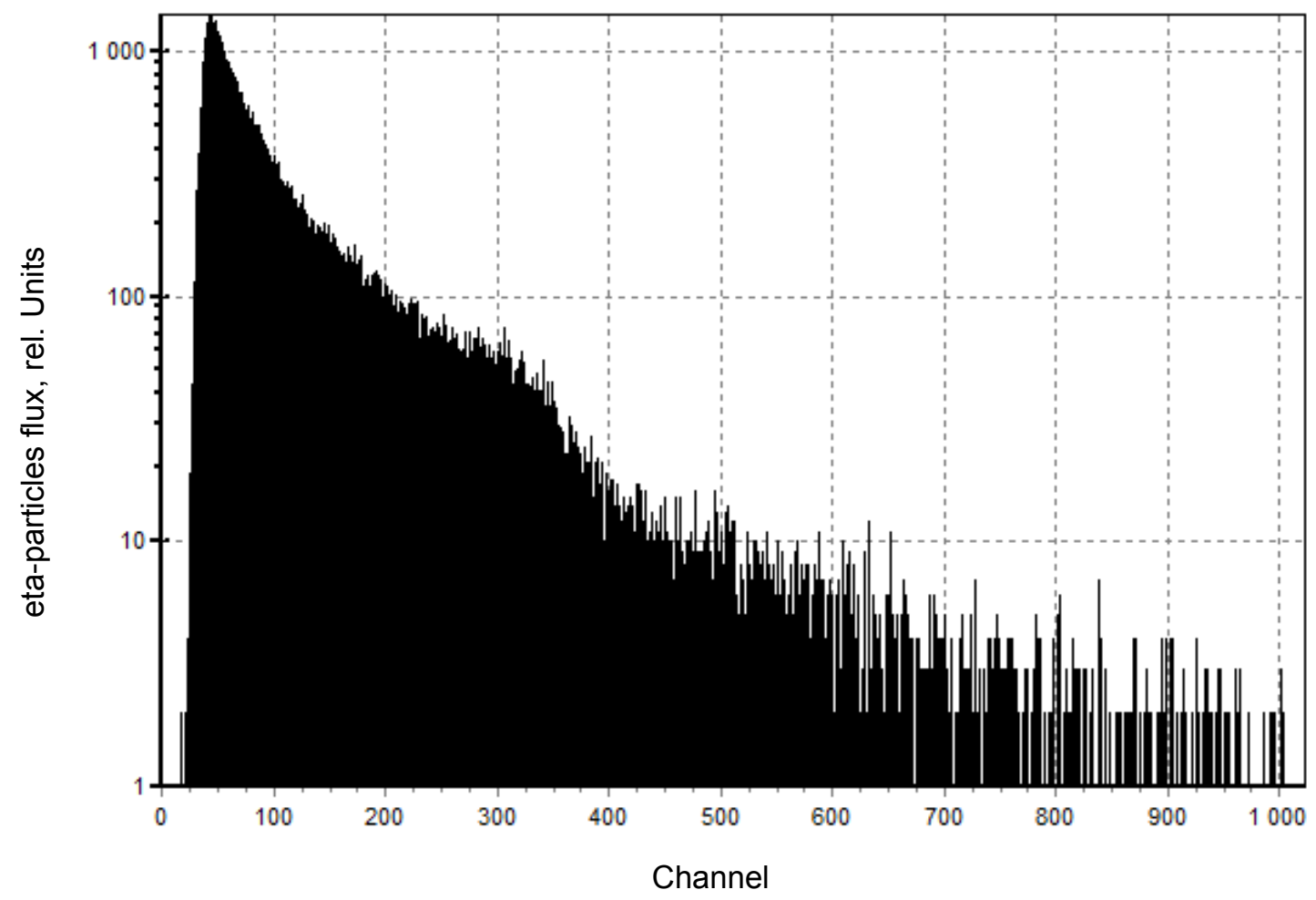

Figure 4 - Typical beta spectrum of radiation background

Figure 5 shows the integral values of the spectra (points) and values averaged over two days (solid line). It is clear that the seasonal variation of natural beta- active radionuclides is traced against the background of diurnal fluctuations. This variation correlates quite well with the variation of radon activity.

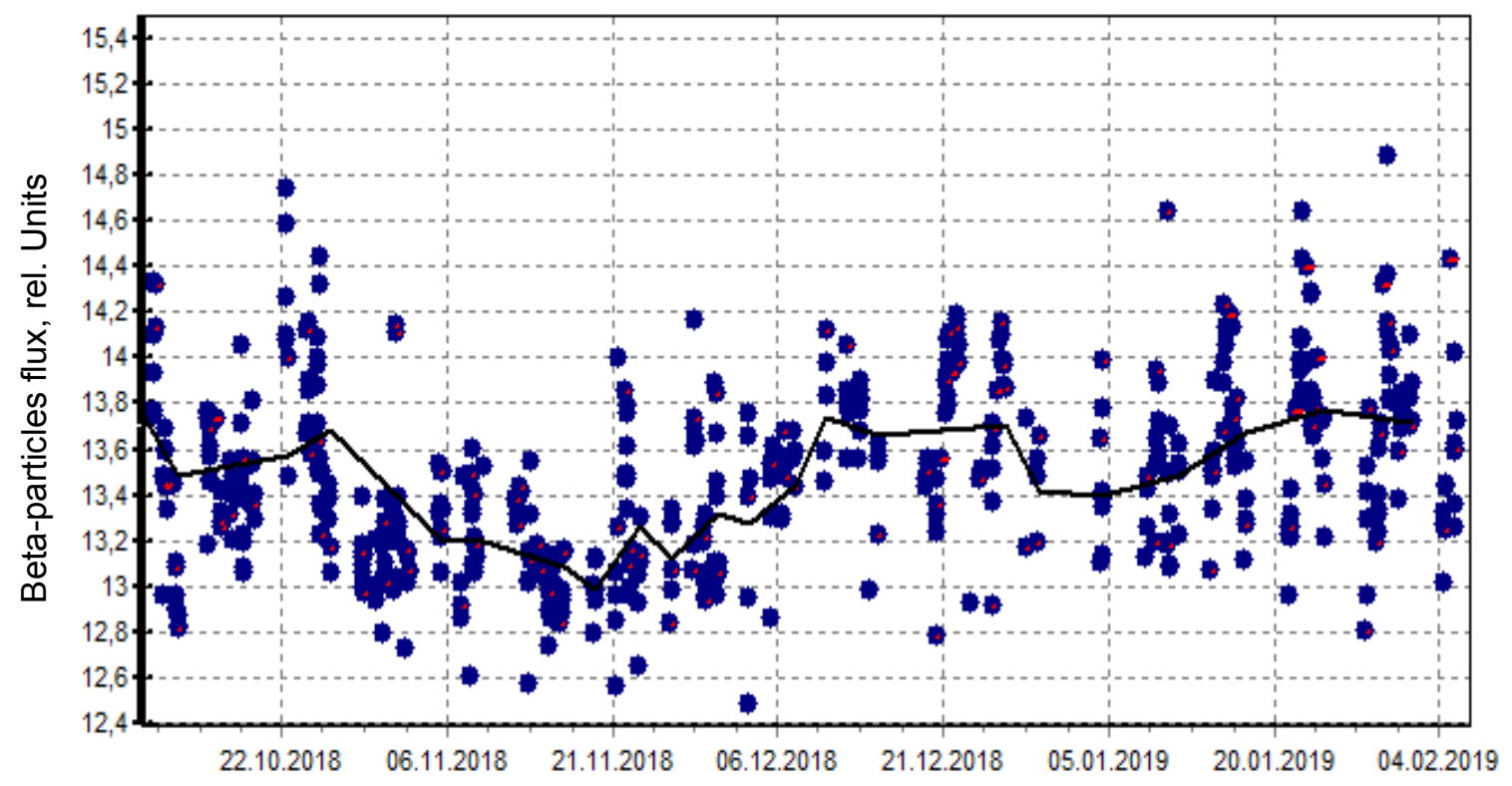

Figure 5 - Time variations of natural beta active radionuclides. 


\section{Conclusions}

The paper presents experimental data of the radon activity for the period from January 2016 to June 2018. The analysis of time variations was carried out by the method of spectral analysis, which showed the presence of existing natural variations, the mechanisms of which were described by the authors in previous works [12, 19-25]. The authors measured the activity of natural beta-active radionuclides of radon daughters in the surface layer of the atmosphere. The measurements were performed with a beta-spectrometer with a "Progress" scintillation detector, which was located on the third floor of the Faculty of Physics and
Technology, al-Farabi KazNU. The time dependence of the integral values of the spectra showed that seasonal variations of natural betaactive radionuclides are manifested on the background of diurnal fluctuations. 1 day, 4 day, 7 day, 16 day and 30 day variations were found.

\section{Acknowledgements}

The work was supported by the state grant financing of basic research (project No. IRN AP05131884 "Fundamental research of the mechanisms of formation of nanoscale oncoradiogenic structures in the body and development of anticancer express devices for their detection").

\section{References}

1. I.L. Knunyants. Short chemical encyclopedia // Moscow. - 2012. - Vol. 4. - 590 p.

2. I.N. Beckman. Radon: enemy, doctor and assistant // Moscow. $-2000 .-205 \mathrm{p}$.

3. Protection against radon-222 in residential buildings and workplaces // Publication 65 of the ICRP, Moscow. 1995. $-78 \mathrm{p}$.

4. Risk of lung cancer due to irradiation with daughter radon decay products indoors // Publication 50 ICRP, Moscow. - 1992. - $112 \mathrm{p}$.

5. I.V. Yarmoshenko, I.A. Kirdin, M.V. Zhukovsky, S.Yu. Astrakhantseva. Meta-analysis of epidemiological studies of the risk of lung cancer during irradiation with radon in dwellings // Medical Radiology and Radiation Safety. - 2003. - Vol. 48. - No. 5. - P. 33-43.

6. J. Milner, C. Shrubsole, P. Das, B. Jones, I. Ridley, Z. Chalabi, I. Hamilton, B. Armstrong, M. Davies, P. Wilkinson. Home energy efficiency and risk of breast cancer: a modelling study // BMJ. - 2014. - Vol. 348. - P.1.

7. I.M. Fisenne, L. Machta, N.H. Harlez. Stratospheric radon measurements in three North American locations // The Natural Radiation Environment VII: VIIth Int. Symp. On the NRE. - 2005. - Vol. 7. - P. 715-721.

8. I.M. Fisenne. Radon-222 measurements at Chester // EML-422. - 1984. - P. 15-149.

9. S. Darby, D. Hill, R. Doll. Radon: A likely carcinogen at all exposures // Annals of Oncology 12. - 2001. - P. 10.

10. Law of the Republic of Kazakhstan No. 219-I of April 23, 1998 "On radiation safety of the population". - 2016.

11. V.N. Sevostyanov. The Problem of radon safety in Kazakhstan // Almaty, 2004. - 212p.

12. V.V. Dyachkov, Yu.A. Zaripova, A.V. Yushkov, A.L. Shakirov, M.T. Bigeldiyeva, K.S. Dyussebayeva, K.E. Abramov. Periodic variations in time of atmospheric radioactive nanoparticles // Physical sciences and technology. 2017. - Vol. 4(1). - P. 20-26.

13. S. Okade. Time variation of the atmospheric radon content, near University of Kyoto // Memoir of College of Science. - 1956. - Vol. 28. - P. 99-115.

14. V.I. Outkin, A.K. Yurkov, S.V. Kridasheev. Dynamics of radon concentration in soil for predicting earthquakes. Proc. Third Eurosymposium on Protection against radon // Liege. - 2001. - P. 137-141.

15. O.N. Kosyanchuk The possibility of using radon exhalation dynamics as a reliable indicator of seismic activity // Young Scientist. - 2011. - Vol.1, No. 11. - P. 53-55.

16. E.V. Bazhko, E.V. Dyachkov, E.V. Ermahanova, E.V. Yushkov. Investigation of permeability of cell membranes under the influence of alpha irradiation of radon isotopes // Collection of reports "Nuclear potential of Kazakhstan", Almaty. - 2011. - P. 138-143.

17. A.V. Yushkov, V.V. Dyachkov. Nuclear-physical mechanisms of the effect of alpha radiation of radon on the cell and the problem of cancer morbidity // Collection of scientific works, Almaty. - 2012. - P. 21-27.

18. Yu.A. Zaripova, A.A. Migunova, V.V. Dyachkov, A.V. Yushkov. Development of nanotechnologies for nuclear medicine // Proceedings of the X-th International Conference, Almaty. - 2013. - Vol. 1. - P. 83-93.

19. V.V. Dyachkov, A.V. Yushkov, A.A. Migunova, A.L. Shakirov, V.A. Sysoev. Development of nanotechnology for creating a radiogenic element base for electronics // Proceedings of the X-th International Conference, Almaty. 2013. - Vol. 1. - P. 62-69. 
20. Yu.A. Zaripova, V.V. Dyachkov, A.V. Yushkov, Z.M. Biyasheva, O. Kh. Khamdieva. Two regularities of radon oncorisium, enhanced by an emanation near the tectonic fault // Collection of theses and reports "Nucleus 2016", Sarov. - 2016. - P. 181-182.

21. V.V. Dyachkov, Z.M. Biyasheva, Yu.A. Zaripova, A.L. Shakirov, A.V. Yushkov. Gravitational interaction of lithospheric substructures and lands with the moon as precursors of destructive earthquakes // Collection of theses and reports "SDFFFO-9", Almaty. - P. 12-14.

22. V.V. Dyachkov, Z.M. Biyasheva, A.A. Komarov, Yu.A. Zaripova, A.L. Shakirov, A.V. Yushkov, O.Kh. Khamdieva, V.A. Sysoev. Experimental observation of four-day variations of radon emanation caused by moon phases // Bulletin of KazNU. Series physical. - 2016. - Vol. 1., No. 56. - P. 120 - 128.

23. V.V. Dyachkov, Yu.A. Zaripova, A.V. Yushkov, A.L. Shakirov, M.T. Bigeldiyeva, K.S. Dyussebayeva, K.E. Abramov. Study of the factor of local accumulation of daughter products of radon decay in the body by the betaspectrometry $/ / 68^{\text {th }}$ International Conference "NUCLEUS-2018" Fundamental problems of nuclear physics, atomic power engineering and nuclear technologies. - Book of abstracts, 2-6 July, Saint-Petersburg, Russia. - 2018. - P. 207.

24. V.V. Dyachkov, Yu.A. Zaripova, A.V. Yushkov, A.L. Shakirov, M.T. Bigeldiyeva, K.S. Dyussebayeva, K.E. Abramov. Study of distribution of beta-pollution in the city of Almaty // Recent Contributions to Physics - 2018. - Vol. 67(4). - P. 4-10.

25. V.V. Dyachkov, Yu.A. Zaripova, A.V. Yushkov, A.L. Shakirov, Z.M. Biyasheva, M.T. Bigeldiyeva, K.S. Dyussebayeva, K.E. Abramov. A Study of the accumulation factor of the daughter products of radon decay in the surface layer using beta spectrometry // Physics of Atomic Nuclei. - 2018. - Vol. 81(10). - P. 1509-1514. 